\title{
A Study on Technophobia and Mobile Device Design
}

\author{
Joong Gyu Ha \\ Industrial Design in Fine Art Education Department \\ Gyeongsang National University, Jinju, Gyeongnam, Korea \\ Tom Page \\ Electronic Product Design in Department Design and Technology \\ Loughborough University, Loughborough, Leicestershire, United Kingdom \\ Gisli Thorsteinsson \\ Design and Craft Education Department \\ University of Iceland, Stakkahlid, Reykjavik, Iceland
}

\begin{abstract}
Technophobia is described as the 'abnormal fear or anxiety about the effects of advanced technology', affecting one third of the population, causing health problems and the inability to work efficiently. The development of the mobile phone, both in its design process and its following socioeconomic success, has a prominent effect on our society in general; this point will be explicated in this paper. The negative effects of these developments have also been assessed with questionnaire-based interviews, focus groups and media analysis in order to focus on those who are most susceptible to the effects of technophobia, to discover the possible causes and to develop a solution for overcoming the phobia. The findings of the literature review and empirical research have been debated; the results proved inconclusive. All age and sex and groups displayed levels of anxiety around technology. Therefore, designers cannot afford to abandon these individuals in the future, and attention should be directed into inclusive product design. Therefore, various solutions have been suggested for support for these sufferers, such as tuition and bespoke, 'built to specification' mobile phones
\end{abstract}

Keywords: technophobia, mobile technology, age and gender

\section{INTRODUCTION}

\subsection{Influence of Mobile Phone development}

Anybody who remembers what mobile telephones looked like five years ago has a sense of the pace at which handheld technology is evolving. Today's mobile devices are not only smaller and lighter than the earliest cell phones; they have become tiny multimedia Internet Terminals' [1].

Technological development has been highly influential in today's society; a revolution that has shaped cultures worldwide [2]. The Global System for Mobile communications (GSM) now accounts for $83 \%$ of the global mobile market [3], displaying approximately 4,800 subscriptions every ten minutes. Technological advances have been the stepping stones to developing highly advanced pieces of technology within our hands; Rheingold [1] suggest phones are no longer simply phones for communication, but that they are desirable, technological consumer products that offer multimedia

${ }^{*}$ Corresponding author.E-mail : hajoonggyu@gnu.ac.kr. Manuscript received May.26, 2011 ; accepted Jun.20, 2011 entertainment features.

The phone industry is a competitive market. During 2002, approximately 423 million phones were sold globally. Nokia alone released more than 30 new handsets onto the global market within that year. In fact designers and manufacturers redesign phones for various reasons: to update the company's appearance to suit current trends; to appeal to different groups of consumers, such as 'Experiencers, Impressers, controllers, maintainers, balancers and sharers'; and to be the first company to add a new feature, or a new combination of functions, if the concept product is not already on the market. This may be to maintain a status as a leading competitor in the mobile market [4].

Careful consideration is given into mobile product design; Nokia is the leading mobile phone manufacturer in the world; the first company to develop an efficient device navigation system on their phones, which has been adopted by other leading brands [5]. The appearance and features of their mobile phones varied depending on the design intent, for example, a phone designed to be simple would have a limited number of control keys and the most basic and simple navigation. 
However, mobile phone design is becoming more complex; Lindholm et al [4] stated that mobile phones offered only basic functions until the 'competitive race for market dominance' proceeded. If mobile companies ignored this push for dominance, the chances of consumers refusing to purchase their products in favour of an alternative handset from another mobile manufacturer would increase. This would not only evoke a loss in sales, but could also damage the consumers' perceptions of that particular mobile manufacture. The race for market dominance is not the only drive for development; the current state of our society demands modern technological products, with smaller, smarter phones with larger screens [4]. This has resulted in the 'squeezing dilemma' for designers;

"In the relatively brief lifetime of the mobile phone, two major technological trends have taken hold; 1) devices tend toward miniaturisation and 2) applications, gestures and functions trend toward expansion. Taken together, they present us with an interesting paradox-squeezing more and more applications into smaller and smaller terminals is how we try and keep users satisfied; but it makes the devices harder to use". [4]

Design Interfaces were also altered with increased technological features. Features which were considered important were initially placed first on menu lists or facilitated with quick-key access, but since features had been developed and added, it became difficult to assess what the most important/commonly used features of the phones were. Therefore, designers faced difficulties designing interfaceseither increase the depth of the menu hierarchy, add more features on the main menu, or add buttons to the phone for quicker access. This in turn, had a knock-on effect on the appearance of the interface, as it had to be approachable for all individuals, whether they were interested in technology or not [4]. Increasing the number of buttons made designs look daunting to those unfamiliar with phones, and some did not understand the concept of the hierarchical menu system. Therefore, it seemed necessary to add more features to the main menu, with the most frequently used options displayed primarily so, understandably, mobile phone design is complicated, and difficult to aim the products at all user types.

It is easy to understand why others feel anxious about electronic interaction. This ultimately can be described as Technophobia. According to Brosnan and Davidson [5], an estimated one third of the population of the industrial world is technophobic to some degree. Brosnan and Thorpe also suggested that avoidance of these technological advances can have implications, academically, socially and mentally, and can affect the quality of life. This is supported by Reingold [1], who implies that a greater divide has been created by technology, between the technophile and the technophobe, limiting the access to information and communication to the latter group.

\section{WHAT IS TECHNOPHOBIA?}

\subsection{The definition of technophobia}

Technophobia is defined as an 'abnormal fear of or anxiety about the effects of advanced technology'. Brosnan [6] stated that technophobia costs the USA economy $\$ 4.2$ billion per year, due to IT applications within the workplace. During 1996, $21.3 \%$ of business managers reported being technophobic to some degree [7]. This proves that technophobia affects societies on a large scale.

Szajna states that technophobia can be caused by a combination of anxiety and perception of the technology being used [8]. Shaw believes that the majority of the population will hold both positive and negative attitudes towards technology [9]. Shaw previously defined technophobia with three statements: a resistance to talking about computers or even thinking about computers; fear or anxiety towards computers; and hostile or aggressive thought about computers.

Rosen [10] expands these definitions into different groups, to define the different types of technophobe: "uncomfortable users' are slightly anxious as they lack enough information about computers or technology to use them effectively'; "Cognitive computerphobes'- many appear cool, calm and collected externally, but are bombarding themselves with negative cognitions internally'; 'Anxious Computerphobes'individuals who exhibit the classic signs of being anxious when using a computer (sweaty palms, heart palpitations etc) [7].

Many may avoid using technology to avoid uncomfortable situations and emotions, such as intimidation, hostility and embarrassment, as well as the fear of breaking the equipment [11], and although these analogies are based on the interaction with computers, mobile phones are evolving into 'smart phones', displaying similar characteristics and functions as computers. It is likely that the same influences will occur with mobile phones.

\subsection{CAUSES OF TECHNOPHOBIA}

\subsubsection{Perception of Technology}

Rheingold [1] described the mobile phone as 'a remote control for your life'. The original concept of the mobile phone, originally designed to make and receive calls, has turned into a multimedia centre within the owners' pocket. While some perceive these advancements as beneficial, others could be deterred to use such a product, possibly because of a small technological-intensive device. This is especially true with regards to devices that appear delicate, in comparison to their cost [4]. Many individuals fear interaction with technology, due to intimidation, and the possibility of damaging the product. Agar believes that these developments of the mobile phone will inevitably lead to more people becoming technophobic, that the increasing complexity of mobile phones will 'destroy' their desirability [12].

Others may avoid interaction with technology, simply because of their beliefs. Eco-Feminists for example, believe computers and technology were created by men, as a method to control women and nature [13]. Techno-Luddites refuse to use technology based on the negative influence it has had on the state of the world [14].

\subsubsection{Technological Experience}


Evidence shows that younger people adopt new technologies better than older generations [1]. This may be due to increased exposure to technology initially introduced at an earlier age by their parents, compared to older generations where such technologies were not available to them in the past [6].

Agar [12] suggests that men during the 1980's were perceived as businessmen, who required mobile phones to remain in constant contact. Men that may have purchased mobile phones in the 1980's would have had time to adapt and develop to follow the development of the mobile phone [6]. Therefore, it could be possible that men with more experience since the release of the mobile phone would feel less anxious around mobile phones than others [15]. This is supported by Brosnan [6], Torkzadeh and Koufteros [16], Todman and Monaghan [17], who all suggested that first interaction with technology would be crucial.

2.2.3 Future Assumptions on the Effect of Technology Marcoulides suggests some people may be nervous of technology [18] because of the change that it will bring, and the influence in society that it will have and the disruption it may cause. The mobile phone has aided incredible revolutions already; the overthrow of President Estrada of Manila in 2001 was organised via text message [1].

Others may be concerned by integrated features; the addition of cameras into mobile phones has been convenient to many. However, the media has illustrated an increase in inappropriate use such as stalking, and 'tele-torture', bullying and physically abusing others, via multimedia messaging [19]. This reluctance to take part or even own mobile phones because of these causes is described as 'Mobile Panic Anxiety' [19].

On a more radical scale, the future intention of scientists could also induce panic about technological advances; with the intention to create Artificial Intelligence (A.I.). Dinello [20] believes that a Cyber-Armageddon will cause 'robosapeins' to dominate the earth, and with some scientists aiming to develop A.I., the possibility of those anxious about its development is a possibility. The Honda Asimo robot, for example, is a real example of A.I. development, but the concept of a machine being able to think and judge for itself can leave some people feeling intimidated and threatened [20].

\section{TECHNOPHOBIA: AGE AND GENDER}

\subsection{Which Members Within Society are Most Likely to be Technophobic?}

There is a divide between the generations with attitudes towards technology. However, one should not assume that the elderly are more technophobic than the young. Todman et al [17] stated that earlier learning and experience tended to influence less anxiety and readiness to use technology. But this is argued by Marcoulides [18], stating this as a misconception.

3.1.1 Adolescence Children and adolescents often use mobile phones as a method of gaining their individual identity and independence [1]. From personal experience, the make or model of the mobile phone often dictated the group that the individual was associated to.
However, owning the right mobile phone for popularity reasons may not necessarily mean the owner would know how to use the product; they may only have it as a status symbol. Adolescent individuals encounter high fears of failure- one of the causes of anxiety and technophobia- and this fear and helplessness is at its strongest influence during puberty [21]. Therefore, if an adolescent encounters a new piece of technology, they may feel unwilling to interact with it. With the increasing features integrated into mobile phones, some adolescents may feel helpless.

3.1.2 The Elderly Raub [22] suggests that the older generations are more anxious than the young with regards to technology. However, Dyck and Smither argue this statement, and discovered after conducting an experiment to compare under $30 \mathrm{~s}$ to over $55 \mathrm{~s}$, that the younger participants actually displayed more anxiety levels than the older individuals, despite having more experience with technology. The researchers believed this was because both the young and the old had expectations that the younger participants would be more literate with the technology, and that the elder participants would be less likely to succeed, therefore reducing anxiety [23[. This theory is supported by Reingold [1], who found that age actually had a negative correlation with computer anxiety, because of the reduced pressure to perform.

3.1.3 Gender Whiteley [24] suggests that new technology is perceived as masculine, and that both males and females conform to this. Females may express higher levels of anxiety and technophobia than males because of this perception. The 'nerd' is notoriously perceived as male, further implying that any interaction with technology should be male based, but there is no perception of a female 'nerd'. Women would therefore gain no social status from being a 'nerd' according to Webster [13].

Huston [25] states that gender associations are made by a child as early as two to seven years of age and believes these gender-appropriate perceptions may be introduced by the child's parents; for example, a father may introduce the child to a computer or another piece of technology, so the child would assign a gender-associative link to the father. Hall and Cooper [26] agree that children indentify sex-role behaviours around their environment and make an associative link, therefore, act accordingly to their sex. This could suggest that females would be more likely to suffer from technophobia than males, simply because of the gender association with technology [27]. Raub [22] supports this, and found that females often reported higher levels of anxiety than males, with more negative attitudes during and after interaction. Further research by Brosnan [27] supports this, which estimated that $99 \%$ of computers in the USA were bought by men. This implies that men show less anxiety than females.

It is not just parents that influence gender association. The media also plays a large part in associations to masculinity. Computer games and technological magazines are often aimed at males, and often depict women as 'sex objects' within magazines [28].

However, sex-type research into technophobia is not consistent. Research suggests that females demonstrating high 
femininity will display higher levels of technophobia, whereas females demonstrating high masculinity will display lower levels of technophobia [6]. Androgynous individuals (those that display roughly the same levels of masculinity and femininity) give a better overview of those more likely to be technophobic . Males with low levels of femininity suppress that femininity and express their masculinity. The opposite is true for sextyped females.

Education may also play a part with perceived genderassociation within technology. Subjects portrayed as masculine in mixed schools, such as Design and Technology, Science and Maths, would attract those with high levels of masculinity. Those with low levels of masculinity would feel repelled due to their perception of the subject as 'cold, unemotional and logical' [29].

Those that displayed high levels of femininity who chose subjects that they perceived as masculine tended to underachieve because of this association [30], possibly because it was seen as 'sex inappropriate' and may have felt unmotivated to perform to their potential [6]. This behaviour could also cause females to defer interaction, thus gaining less experience, which in turn would cause more negative attitudes to develop [27]. However, Single sex schools will not have masculine influences upon subjects. Therefore, within these surroundings, females demonstrated that masculine perceptions of technology would not be developed [31].

Popovich[32], Hall and Cooper [26] believed women would use technology when they would serve a purpose as a tool or aid. This is supported by Brosnan [27] and Turkle [33], who stated that females would be 'soft masters', who would use computers for 'useful' tasks with a purpose and would see technology as something to conform to. Turkle believed that if women used a different approach, interaction could cause anxiety, negative feelings and technophobia. Males ('hard masters') on the other hand, would tend to use technology for 'abstract exercises', and would see technology as something to take control with.

The gender perception of mobile phones among men and women could also depict their typical use today. Advertising during the 1980's made the assumption that businessmen would need a mobile phone to stay in constant contact with work [12]. Women on the other hand were perceived as the weaker race; mobile phones were advertised as 'safety blankets' to provide a source of security if they were left stranded in unfamiliar grounds. The outcome of this would be a distinct stereotypical split, which would narrate the future perceptions of the way the mobile was viewed. This still applies to today's consumer audience; parents purchase mobile phones for their children as a safety device, the elderly purchase mobile phones as a safety precaution in case of an incident, and others may keep a mobile phone in close proximity during travel, such as the glove box in case of a breakdown. People may purchase mobile phones regardless of being technophobic, in the fears that they may need to get into contact in an emergency.

\section{EMPIRICAL DATA}

In order to assess technophobia amongst different age groups and sex-types, it was necessary to carry out empirical research. The method of collection was considered carefully in order to address different groups including those with different social backgrounds. Since the research was based on technophobia, it was vital that the collection methods were not presented electronically, (i.e. email-based questionnaires) since this would have potentially disregarded those that were technophobic.

\subsection{Literature Review and Research Methods}

The work of Saris 2007 was used to decide the most appropriate data collection method. Table 1 summarises the strengths and weaknesses of the different data collection techniques. it was decided that a one-to-one structured interview, a focus group and media research would be carried out.

Table 1: Research methods-strengths and weaknesses Research Method: One-to-one questionnaire/interview

- Strengths

- Better reliability than dispersed questionnaires.

- Chance to clarify questions/answers to ensure total understanding.

- Weaknesses

- Time Consuming

- Due to time consumption, participants may give any answer to speed the process up

Research Method: Dispersed questionnaire

- Strengths

- Quick

- Inexpensive

- Simple to carry out (Quantitative questionnaires) are easy to analyse

- Weaknesses

- Validity of answers can be questionable

- People may get inpatient during completion, and may give the first answer they see

- Questionnaires via Email/post may be ignored-no clarification that it will return (In this circumstance, dispersing questionnaires via email would only get answers from those that are comfortable with technology; it would not address those that the research is trying to discover).

- Research Method: Focus groups

- Strengths

- Gains in-depth, qualitative responses

- Discussion can develop some interesting answers, as

well as both sides of a debate

- Weaknesses

- People may feel embarrassed to answer differently to others

- One participant will dominate; this can silence the other participants

- Research Method : Observational research 


\section{- Strengths \\ - The behaviour of participants can be observed when exposed to a certain situation, or given a task to perform \\ - Weaknesses \\ - Observation will affect the outcome, as it may make the participant feel uncomfortable \\ - Time Consuming \\ - Ethical issues regarding exposure to uncomfortable situations}

\subsection{One-To-One Questionnaire-Based Interview}

The aims were to investigate the proportion of those who do/do not own mobile phones, with regards to age, sex and perception of gender-appropriateness influences of technology. Questionnaires were created, and formed the basis of a structured, one-to-one interview. 51 individuals were asked to participate in the interviews, 37 agreed to participate. Six age groups were organised and selected.

- Ages 10 and under : One participant was selected randomly in a busy town centre, accompanied by his parents.

- Ages 10-14 : Participants were selected randomly within a busy town centre.

- Ages 15-24 : Participants were chosen within a secondary school (De Lisle Catholic School, Leicestershire).

- Ages 24-44 : Participants were chosen randomly within a busy town centre.

- Ages 45-64 : Participants were chosen randomly within a busy town centre, and within a local supermarket.

- Ages 65+ : Participants were chosen randomly within a rest home, based in Hampshire (St. Georges).

The question structures were carefully considered 'requests for answers' [34]; These requests provided closed answers for quantitative results which were easier to analyse. Response Scales were also introduced in the questionnaire, to enable participants to rate their emotional responses. The word 'Technophobia/technophobic' was not mentioned throughout the questionnaire, so participants did not pre-determine their answers to appear/not appear technophobic.

\subsection{Media Research}

The aim of this was to investigate whether the media illustrates mobile phones/ new technology as a masculine product. Literature support/evidence; Robins [35], suggested that Media depicts computers and other technology as a masculine product, and that the media encourages this, by providing technological-based media/literature aimed at men. The research method involved: three popular male magazines were purchased, as well as three popular female magazines (popularity was determined by the highest sales figures within each male and female category (Tesco's stores, 2008). The number of phone images shown was recorded for each magazine.

\subsubsection{Results and discussion;}

- Male Magazines;
- Nuts (Smalley, 28 March-3 April 2008); 11

- T3 (Brook, April 2008);

- Stuff (Dunmore, April 2008);

- Feale Magazines;

- Ok! Magazine (Moody, M. March 25 2008);

- Heat (Frith, 29 March 2008);

- Elle (Candy, April 2008);

These results illustrated that the media does depict technological products as a masculine domain, with the women on the front page holding new electronic products.

\subsection{Focus Group}

The aims of this research method are to gain more quantitative answers from participants, from a range of backgrounds, ages, and sex-types about their perception of technology, and to investigate any fears or problems they have with mobile phones. The method comprised: five participants engaged in the focus group. Various questions were asked throughout the discussion, but were kept to a minimum, to encourage participants to talk freely. The discussion was also recorded using an MP3 player/recorder.

4.4.1 Results and Discussion Overall, each participant had a valid contribution. One female participant claimed she used her mobile phone as a safety blanket whilst walking to and from work, so she could contact her mother, which made her feel secure. She also enjoyed the opportunity to text/phone her friends when she was bored or lonely. Another participant of the same age, however, felt that his mobile phone was more like a tool; an extension to the office that was used for business communication and nothing more, and said that he would quite happily live without a mobile phone given the chance.

Another female participant claimed that she owned a mobile phone, but had no need for it. It was important to note that this participant was often reluctant to interact with technology, so her claim of having no need to use it could have been to avoid interaction as a coping strategy

\section{DISCUSSION}

\subsection{Sex-types; are females more technophobic than males?}

After analysing the questionnaire results, only one female and seven males did not own a mobile phone. This is interesting considering many psychologists believe that technology is perceived as masculine. The elderly groups (both men and women) had mobile phones, mainly for emergencies. This is supported by one participant within the focus group, a twenty-six year old female, who stated that she used her mobile phone as a security blanket, and gave her comfort. This evidence supports the findings of Agar [12]. However, there is no conclusive evidence from the questionnaire results to prove that females are more technophobic than males.

The same female participant from the focus group also stated that she was afraid of using phones in case she broke them, so even though this participant seemed to rely highly on her mobile phone for security, she also feared the technology. Shaw [9] and Brosnan [27] can support this approach, that most 
individuals suffer from technophobia to some degree. This can be supported with findings from the questionnaires; one other female participant concurred with this feeling of a fear from breaking the product. Brosnan [27] also supports this as a valid contribution to anxiety and the lead to technophobia.

One participant saw her mobile phone as a must-have; an aid in social contact. However, one male participant claimed that his mobile phone was used purely as a contact tool for business, which he used only as a tool and never for social communication. This finding contradicts the work of Popovich [32], who claimed that women saw technology as a tool, and would therefore only use it if it was necessary. This contradiction could be because Popovich's findings were based on computer/IT research, whereas this research is based on mobile phones. Even so, it is interesting to note these inverse findings, as one could argue that therefore, females do not perceive the mobile phone to be masculine, and would not avoid using them because of gender-inappropriate behaviour, as stated in section 5.2 (Gender). Rheingold [1] could support this theory, as he claimed that female adolescents in Japan were the most common mobile-phone users. This is also supported by the findings of the questionnaire, that all but one female participant claimed that they had a mobile phone. Males could, in this circumstance, see the mobile phone as a feminine product, which could be why males use their mobile phones as tools instead.

However; the media research still demonstrates that technology is still perceived as masculine. The concept of 'geek' is dominant here, with the assumption that geeks and nerds are males; hence the larger amount of technological publicity in masculine magazines. Webster [13] can support this; that the nerd/geek stereotypes are often portrayed as males, and therefore females have no social networking if females considered themselves interested in technology. This cannot be so, since 3 male and 3 female participants claimed to purchase their mobile phones because of the features it offered.

\subsection{Age Differences:}

\subsubsection{Are older people more technophobic than younger generations?}

10 participants between the ages of 15 to 24 from the questionnaire-interviews stated that they owned mobile phones in the past. Therefore, one could assume that they have had experience in using mobile phones before, and would therefore feel more comfortable using them than other groups. This is supported by Raub [22] and Taylor et al [36]. None of the 1014 or 15-24 participants had difficulty in learning how to use their mobile phones. However, one female participant in this age group stated that they felt anxious around technology.

Results from the questionnaire suggested that the younger generations were more interested in the mobile phones for social contact. This is supported by the work of Taylor et al [36] and Rheingold [1], as explained in section 5.1.1. They were also more concerned with the appearance of the phones, which influenced their choice of mobile phone purchase.

Literature research suggested that the elderly had less interaction with technology in their lifetimes than younger generations, and could therefore suggest that the elderly would not own new technologies, possibly because of the fear of not knowing how to operate it. However, nine out of the eleven questionnaire participants in the age group $65+$ owned a mobile phone. The two participants within this group that did not own mobile phones did not express their reasoning's with anxiety or nervousness around technology, but stated that they did not want to be contacted easily (one participant claimed he served in the Second World War and wanted to be left undisturbed) and could not own a mobile phone because of the cost of the handset/contract.

Most of the over 65's claimed to have selected their mobile phones because they were simple to use and only used them for emergencies. However, there was one participant that chose their mobile phone because it had all up-to-date features and used it on a daily basis. This is an interesting finding, and proves that age may not be a consistent factor with regards to technophobia. Even though 6 out of the eleven $65+$ participants claimed to feel uncomfortable around technology, other age groups demonstrated similar diversity in comfort as well, with one individual in the 15-24 age group feeling uncomfortable around technology. This conforms to Raub's research [22], who believed that age had no influence on anxiety or technophobia.

However, the majority of participants within the $65+$ age group claimed to have owned their mobile phones for longer periods of time than younger generations, with 4 people owning phones for 2-5 years, and four other participants owning phones over five years. This could suggest that their phones had very 'basic' features compared to the newest handsets available, and that they were chosen because they were easier to use. However, the reason behind choosing a simple phone is still uncertain. It could be because the elderly only wanted the phone to make basic phone calls, or because of problems such as arthritis or poor eyesight which could restrict function usage; number buttons have become notoriously smaller on newer mobile phones, as described by Lindholm et al [4], to compact more features into smaller handsets. One participant in the focus group expressed his problems with his mobile phone, because of the button sizes being too small. The participant claimed that he had to use his thumb nail to press the keypads, which, as an elderly individual, he found extremely frustrating and uncomfortable. The elderly may have problems with this physical size, so many might have basic phones as they tended to have larger buttons, with the overall dimensions of the phone being larger and easier to hold. This may also be why the majority of the elderly use the phone to make phone calls rather than texting people. However, some may not have wanted up-to-date phones because the anxiety caused by the introduction of new features. This reason could indicate levels technophobia.

Participants in all age ranges that owned mobile phones claimed that there were features that they did not need, and the concept of having a 'built to specification' mobile phone seemed to appeal to many. Although some favoured the feature-packed handsets, many felt that various features were unnecessary, with the video call function being the most unpopular. However, different features appealed to different groups; the young were in favour of texting and multimedia tools, such as the MP3 player; the 25-44 year old and 45-54 
year old age groups were in favour of phone calls, with higher usage of built-in GPS where available and less usage of MP3 players/games, and the elderly tended to use only the phone call function, but the camera seemed a common favourite throughout all the groups. However, this highlights the different needs/wants of different age groups, so the concept of building phones similar to building computers seems an interesting solution, to reduce the amount of unnecessary functions in order to make operation easier, and possibly make handsets cheaper.

\section{CONCLUSION}

Research has concluded that technophobia with regards to age and sex-types is inconclusive. It should be mentioned that Sievert [37] found no relation between age, gender or education with regards to technophobia during his research. Therefore, no generalisation can be established in order to combat technophobia to a particular age/sex-type group. It was concluded that designers need to pay more attention to the needs of the technophobe. They should not be abandoned in a society where interaction with technology is becoming the perceived 'trend'. This is supported by Kelley and Charness [38].

The concept of 'built for all' does not work for mobile phones. Years have been spent on research by companies like Nokia, to find an effective solution to navigate easily around mobile phone interfaces. Therefore, there is little improvement that can be made in physical button design. Also designers should take so drastically to incorporate different strategies to help those that do suffer from technophobia.

\subsection{Design Outcome}

One design strategy to overcome the fear of breaking the product could be to make the appearance more rugged. The aesthetics should be concentrated on to give the impression that the phone will withstand rough treatment, as well as having an obvious 'exit' button so the user could easily cancel any error that they made.

A 'build to specification' approach to mobile phones could be adopted, in order to provide users with features they wanted rather than a set specification. This principle would be a similar approach to personal computer building. Tuition may also be an option for those that are uncomfortable because of fears of breaking the mobile phone. This service could be offered when purchasing a phone. Ahtisaari [39] made an interesting assumption that people learn by observation, not by reading manuals.

Gummar [40] suggested that anxiety reduction was influenced by the perceived sense of control, so users should be encouraged to feel in control of the product. Therefore, technophobic users should be given the opportunity to observe and learn how to use the product, and, if necessary, aim to change their perception if they hold inappropriate thoughts of technology to gain control of the product [41]. Such a control can be linked back to the overall design of the product. Although the history and development of the mobile phone has had an immense influence on the world, there are still improvements to consider for designers. Since an approximately one third of the population technophobic designers are not supposed to ignore the sufferers.

\section{REFERENCES}

[1] Rheingold, H., Smart Mobs; the Next Social RevolutionTransforming Cultures and Communities in the age of Instant Access, Cambridge, MA, USA, 2002.

[2] Goggin, G., Cell phone culture: mobile technology in everyday life, London, Routledge, 2006.

[3] GSM world, GSM World: Home- Global GSM and 3GSM mobile Connections, 2008. Available at http://www.gsmworld.com/index.shtml [Accessed 28 Nobember 2009]

[4] Lindholm, C., Keinonen, T., Kiljander, H., Mobile Usability: How Nokia changed the face of the mobile phone, McGraw-Hill, London, 2002.

[5] Brosnan, M., Davidson, M., "Computerphobia: is it a particularly female phenomenon?" The Psychologist, 7 (2), 1994, pp.73-78 Cited in: Brosnan, M., Technophobia; The Psychological impact of Information Technology, Routledge, London, 1998.

[6] Brosnan, M., Paper presented at the Computers in Psychology Conference 1995. York University. Cited in: Brosnan, M., Technophobia; The Psychological impact of Information Technology, Routledge, London, 1998.

[7] Bozionelos, N., "Psychology of computer use: XXXIX. Prevalence of computer anxiety in British managers and professionals". Psychological reports, 78(3, 1) pp.9951002, 1996, p136, Cited in: Brosnan, M., Technophobia; The Psychological impact of Information Technology, Routledge, London, 1998.

[8] Szajna, "An investigation of the predictive validity of computer anxiety and computer aptitude", Educational and Psychological Measurement, 54(4), pp.926-934, 1994 Cited in: Brosnan, M., Technophobia; The Psychological impact of Information Technology, Routledge, London, 1998.

[9] Shaw, "Harris Poll shows public is high on computers" Mini Micro systems, Feb 55, 1984, Cited in: Brosnan, M (x), Technophobia; The Psychological impact of Information Technology, Routledge, London, 1998.

[10] Rosen, L.D., Sears, D.C., Weil, M.M., "Computerphobia. Behaviour Research methods", Instruments and Computers, 19, pp.167-179, 1987.

[11] Ahl, D.H., Survey of Public attitudes towards computers in society. In D.H. Ahl (ed) The best of Creative computing. 1, pp.77-79., 1976, Morrison NJ: Creative Computing Press. Cited in: Brosnan, M., Technophobia; The Psychological impact of Information Technology, Routledge, London, 1998.

[12] Agar, J., Constant Touch-A Global History of the Mobile Phone, Icon Books Ltd, Cambridge, 2004.

[13] Webster, J., Shaping women's work: gender employment and information technology. London, 1996: Longman Cited in: Brosnan, M., Technophobia; The Psychological impact of Information Technology, Routledge, London, 
1998.

[14] Sale, K., Rebels, Against the future: lessons for the computer age. London, 1996., Quartet books Cited in: Brosnan, M., Technophobia; The Psychological impact of Information Technology, Routledge, London, 1998.

[15] Loyd, B.H. and Gressard, C.P., "Gender and computer experience on computer attitudes", AEDS Journal, 18, pp.67-77, 1984., Cited in: Brosnan, M., Technophobia; The Psychological impact of Information Technolog', Routledge, London, 1998.

[16] Torkzadeh, G., Koufteros, X., "Factorial validity of a computer self-efficacy scale and the impact of computer training", Educational and Psychological Measurements, 54 (3), pp.813-821, 1994., Cited in: Brosnan, M., 'Technophobia; The Psychological impact of Information Technology', Routledge, London, 1998.

[17] Todman and Monaghan, "Qualitative differences in computer experience, computer anxiety and students use of computers: a path model", Computers in Human Behaviour 10(4) pp.529-539, 1994., Cited in: Brosnan, M, Technophobia; The Psychological impact of Information Technology, Routledge, London, 1998.

[18] Marcoulides, G.A., "The relationship between computer anxiety and computer achievement", Journal of Educational Computing Research, 4, pp.151-158, 1988., Cited in: Brosnan, M., Technophobia; The Psychological impact of Information Technology, Routledge, London, 1998.

[19] Ling, R., The Mobile Connection: The cell phone's impact on society, Morgan Kaufmann Publishers, San Francisco, USA, 2004.

[20] Dinello, D., Technophobia! science fiction visions of posthuman technology, University of Texas Press, Austin, Texas USA, 2006.

[21] Carver, C., Blaney, P. and Scheier, M., "Reassertion and giving up: the interactive role of self-directed attention and outcome expectancy", Journal of Personality and Social Psychology, 36, pp.324-332, 1979., Cited in: Brosnan, M., Technophobia; The Psychological impact of Information Technology, Routledge, London, 1998.

[22] Raub, A., "Correlates of computer anxiety in College students", Doctoral Dissertation. University of Pennsylvania. Dissertation Abstracts International 42:4775A, 1981., Cited in Brosnan, M., Technophobia; The Psychological impact of Information Technology, Routledge, London, 1998.

[23] Ryan et al, "Attitudes towards younger and older adults learning to use computers", Journals of Gerontology 47(2) pp.96-101, 1992., Cited in: Brosnan, M., Technophobia; The Psychological impact of Information Technology, Routledge, London, 1998.

[24] Whiteley, B., "Gender differences in computer-related attitudes and behaviour: a meta-analysis". Computers in Human Behaviour, 13(1), pp.1-22, 1997., Cited in: Brosnan, M., Technophobia; The Psychological impact of Information Technology, Routledge, London, 1998.

[25] Huston, A. C., "The development of sex typing: themes from recent research", Development review, 5, pp.1-17, 1985, Cited in: Brosnan, M., Technophobia; The
Psychological impact of Information Technology, Routledge, London, 1998.

[26] Hall, J. Cooper, J., "Gender, experience and attributions to the computer", Journal of Educational computing research, 7 (1) pp.51-60, 1991., Cited in: Brosnan, M., Technophobia; The Psychological impact of Information Technology', Routledge, London, 1998.

[27] Brosnan, M.,Technophobia; The Psychological impact of Information Technology, Routledge, London, 1998.

[28] Chen, M. "Gender and computers: the beneficial effects of experience on attitudes", Journal of Educational Computer Research 2, pp.265-282, 1986., Cited in: Brosnan, M., Technophobia; The Psychological impact of Information Technology', Routledge, London, 1998.

[29] Wienrich-Haste, H.E, "The image of science" In A. Kelly, the missing half, Manchester University Press, Manchester, 1981, Cited in: Brosnan, M., Technophobia; The Psychological impact of Information Technology', Routledge, London, 1998.

[30] Smail, B. and Kelly, A., "Sex differences in science and technology among eleven year-old school children IIattitudes", Research in Science and Technology Education, pp.1-10, -p48, 1984, Cited in: Brosnan, M., Technophobia; The Psychological impact of Information Technology', Routledge, London, 1998.

[31] Culley, L., "Girls, boys and computers". Educational Studies 14(1), pp.3-8 1988., Cited in: Brosnan, M., Technophobia; The Psychological impact of Information Technology', Routledge, London, 1998.

[32] Popovich, L., "The development of the attitudes toward Computer Usage Scale". Educational and Psychological Measurement, 47,pp.261-269, 1987., Cited in: Brosnan, M., Technophobia; The Psychological impact of Information Technology', Routledge, London, 1998.

[33] Turkle, S., "Computational reticence- why women fear the intimate machine", In C.Kramarae, (ed), Technology and women's Voices. London, 1988. Routledge Cited in: Brosnan, M., Technophobia; The Psychological impact of Information Technology', Routledge, London, 1998.

[34] Saris, W. E., Design, Evaluations and analysis of questionnaires for survey research, Chichester, 2007.

[35] Robins, K., "Forces of consumption from the symbolic to the psychotic", Media, culture and society, 16(3), pp.449468, 1994., Cited in: Brosnan, M., Technophobia; The Psychological impact of Information Technology', Routledge, London, 1998.

[36] Taylor, A., Harper, R., "Talking 'Activity': Young people and Mobile phones", paper presented at the CHI 2001 Conference on human factors in Computing systems, Seattle, 21 March-5 April. http://research.microsoft.com/ ast/files/Taylor_\&_Harper 01.pdf [Accessed 11 April 2008]

[37] Sievert, M., "Investigating Computer anxiety in an academic Library", 1988., Information Technology and Libraries, Sept pp.243-252., Cited in: Brosnan, M., Technophobia; The Psychological impact of Information Technology', Routledge, London, 1998.

[38] Kelley, C. And Charness, N., "Issues in training older adults to use computers. Behaviour and Information 
Technology", 14 (2), pp.107-120., 1995, Cited in: Brosnan, M., Technophobia; The Psychological impact of Information Technology', Routledge, London, 1998.

[39] Ahtisaari, M., "social Mobility-Out of the blue"- the J. Walter Thompson Magazine for Europe, 2000/2001Cited from Rheingold, H., Smart Mobs; the Next Social Revolution- Transforming Cultures and Communities in the age of Instant Access, Cambridge, MA, USA, 2002

[40] Gummar, M.R., "Control, Warning signals, and distress in infancy", Developmental Psychology 16, pp.281-289, 1980, Cited in: Brosnan, M., Technophobia; The Psychological impact of Information Technology', Routledge, London, 1998.

[41] Teh, G and Fraser B., "Development and validation of an instrument for assessing the psychological environment of computer assisted learning classrooms", Journal of Educational Computing Research, 12 (2), pp.177-193, 1995.

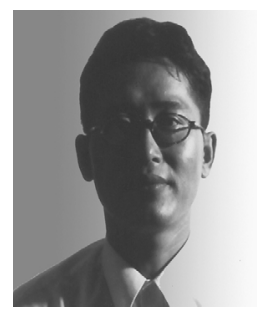

\section{Joong Gyu, Ha}

He obtained his B.A. and M.A. in Industrial Design from Hong-Ik University, Seoul, Korea, in 1985, 1987 respectively. $\mathrm{He}$ was associated with BioDesign Innovation Centre in Korea as CEO from 2003 to 2005 and was a visiting scholar in Sustainable Design in the Department of Design and Technology at Loughborough University, Leicestershire, England. He has won the 'Best Design Award' from the 2009 Exhibition of Invited International Designers, 16 countries around the world's representative industrial and environmental designer participating in Busan, Korea. He is a professor of Industrial Design in the Department of Art Education at Gyeongsang National University, Korea, from 1988 to present. His research interests include the sustainable product design education for industrial designers and environmental designers.

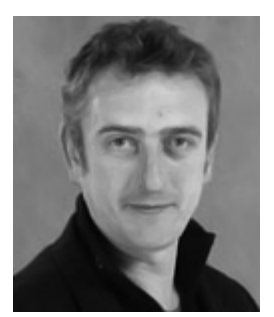

\section{Tom Page}

He obtained his BSc. and M.Phil in Engineering Design from Napier University, in 1988 and 1992. He obtained a $\mathrm{PhD}$ from the University of Hertfordshire in 2002. He is an external examiner on Engineering and Manufacturing programmes at Sheffield Halllam University. $\mathrm{He}$ is a visiting scholar at Iceland University and the University of Lapland in Finland and has been an external examiner on undergraduate fields in Product Design and Manufacturing Engineering at the University of East London. (2008 to present) He is a lecturer in Electronic Product Design in Department Design and Technology at Loughborough University, 2003 to present. Among his main research areas are in the research and development of computer applications for design and technology education, logistics and supply chain management and electronic product design.

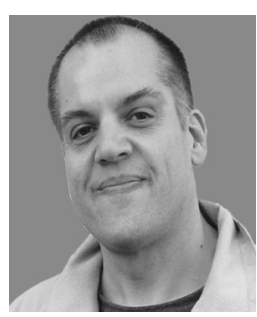

\section{Gisli Thorsteinsson}

He obtained his B.Ed. in 1980, in Design and Craft Education from the University of Iceland and his $\mathrm{PhD}$. from Loughborough University,

Leicestershire, England in 2010. Gisli has been the Chairman of the Association of Icelandic Industrial Arts Teachers since 1995. From 2000 he has been on the Board of 'Nordfo', the Pan Scandinavian co-operative researching Art and Design projects in Scandinavia. Gisli has been an Assistant Professor at the University of Iceland, since 1996, in the Department of Design and Craft Education. His main research focus has been on exploring the values of using Virtual Reality Learning Environment for supporting the development of ideation skills in students, in Icelandic schools. 